\title{
Risk factors in malignant transformation of gastric epithelial neoplasia categorized by the revised Vienna classification: endoscopic, pathological, and immunophenotypic features
}

\author{
Sung Hoon Jung ${ }^{1}$, Woo Chul Chung ${ }^{1}$, Kang-Moon Lee ${ }^{1}$, Chang Nyol Paik ${ }^{1}$, Ji Han Jung ${ }^{1}$, Min Kyoung Lee ${ }^{2}$, \\ Yun Kyung LeE ${ }^{3}$, and In-Sik Chung ${ }^{1}$ \\ ${ }^{1}$ Department of Internal Medicine and Pathology, College of Medicine, the Catholic University of Korea, Seoul, Korea \\ ${ }^{2}$ The Research Institute of St. Vincent Hospital, the Catholic University of Korea, Suwon, Korea \\ ${ }^{3}$ Department of Pathology, Samsung Medical Center of Korea, Seoul, Korea
}

\begin{abstract}
Background. According to the revised Vienna classification, the surgical removal of gastric epithelial neoplasia category 3 (low-grade dysplasia) lesions is not necessary, whereas the removal of category 4 lesions (high-grade dysplasia and intramucosal cancer) is obligatory. However, approximately $15 \%-30 \%$ of low-grade adenomas/dysplasia progress to highgrade lesions or adenocarcinoma, and it is difficult to determine which lesions will advance to true malignancy. The aim of this study was to evaluate the endoscopic, pathological, and immunophenotypic differences between category 3 and 4 lesions according to the revised Vienna classification.

Methods. All tissue samples were excised by endoscopic mucosal resection. Fifty-two category 3 tissue samples and 54 category 4 samples were evaluated by endoscopic findings; by pathology examination of the surrounding mucosa; and by CD10, MUC2, MUC5AC, MUC6, and RUNX3 immunohistochemical staining.

Results. Univariate analysis showed that the size of the lesion, color change, ulceration, gastritis score of the surrounding mucosa, and positive expression of MUC6 were associated with category 4 lesions. Multivariate analysis showed that the size of the lesion, ulceration, and positive expression of MUC6 were strongly associated with category 4 lesions.

Conclusion. Lesions more than $17 \mathrm{~mm}$ in diameter or lesions that are associated with ulceration have the potential for malignant transformation. Positive immunoreactivity for MUC6 appears to be a complementary marker for malignant transformation of gastric epithelial neoplasia.
\end{abstract}

Key words Vienna classification · Gastric epithelial neoplasia $\cdot$ MUC6

Offprint requests to: W. C. Chung

Department of Internal Medicine, St. Vincent Hospital, the Catholic University of Korea, 93-6 Ji-dong, Paldal-gu, Suwon, Gyunggi-do, Korea 442-723

Received: November 3, 2009 / Accepted: March 10, 2010

\section{Introduction}

Gastric epithelial dysplasia and gastric adenomas have been considered to be precancerous lesions with a variable clinical course. Some progress to adenocarcinomas, whereas others persist unchanged for a long time [1,2]. The absence of a uniform classification for gastric epithelial dysplasia/gastric adenomas has caused confusion regarding the features that differentiate preinvasive from early gastric cancer lesions. This diagnostic inconsistency leads to inappropriate treatment and has often resulted in overtreatment of gastric mucosal neoplasias by surgical resection $[3,4]$. Therefore, a uniform classification is needed, with reproducible criteria that have minimal inter- and intraobserver variability.

For the practicing physician, the classification should be simple and reflect the available therapeutic options. Since 2000, the revised Vienna classification has helped to provide guidance for clinical management $[5,6]$. The removal of category 3 lesions (low-grade dysplasia), based on that classification, is not necessary, whereas the removal of category 4 lesions (high-grade dysplasia and intramucosal cancer) is obligatory, because more than $80 \%$ of high-grade adenomas progress to adenocarcinomas [7]. However, there are frequently cases that do not easily fit into the diagnostic categories; $15 \%-30 \%$ of low-grade adenomas progress to high-grade adenomas or adenocarcinomas $[8,9]$. Therefore, it is difficult for clinicians to determine which low-grade adenomas will progress. To date, only a few studies have determined the risk factors for malignant transformation of gastric epithelial dysplasias, stratified by subgroups specific for the dysplastic grade $[10,11]$. The goal of the present study was to compare the endoscopic findings, pathology of the surrounding mucosa, and the immunophenotype of category 3 lesions (low-grade dysplasia) with these findings in category 4 (high-grade dysplasia and intramucosal cancer) lesions, according to the revised Vienna classification. 
The Runt family of transcription factors consists of three members: RUNX1, RUNX2, and RUNX3. All three RUNXs play important roles in both normal developmental processes and carcinogenesis [12]. Especially, RUNX3 is necessary for the suppression of cell proliferation of the gastric epithelium. It is known that primary gastric cancer specimens express significantly lower levels of RUNX3 than normal tissue, because RUNX3 exerts its tumor suppressor activity [13, 14]. We explored the role of RUNX3 in early gastric carcinogenesis.

\section{Methods}

\section{Materials}

Human samples were used according to the guidelines of the Ethics Committee of the Catholic University of Korea. All tissues were therapeutically excised by endoscopic mucosal resection from May 2004 to June 2008. The diagnosis of the tissue samples, according to the revised Vienna classification, was confirmed by two different histopathologists; when they disagreed, the tissue sample was excluded from the study.

\section{Endoscopic findings of gastric epithelial neoplasia}

Two different specialists re-evaluated the endoscopic findings by reviewing the imaging archiving communication system. The lesion variables analyzed were the size (largest diameter), type (prominent, flat, or depressed), color change (red, white, or no change), ulceration (presence or absence), location of the lesion (antrum or body), and the extent of atrophy (closed or open type).

\section{Pathology examination of surrounding mucosa}

All normal surrounding tissues examined were grossly intact mucosa at least $1 \mathrm{~cm}$ from the mucosal lesion that had been removed as gastric biopsy specimens just after endoscopic mucosal resection. Microscopic examination showed no evidence of malignant cells. Each patient was classified as Helicobacter pylori-positive or -negative according to the histological results (silver stain or CLO test).

To evaluate the pathological association between gastric cancer and gastritis patterns, we focused on the inflammation of the gastric mucosa adjacent to the lesions. A gastritis score was calculated for the surrounding mucosa, based on the summed values of the grade and the activity of gastritis. Grading of the variables associated with gastritis (infiltration by lymphocytes and plasma cells) was performed using the updated Sydney system [15], a scoring system ranging from
$0=$ none to $3=$ severe. Gastritis activity was based on infiltration by neutrophilic granulocytes and was scored according to the updated Sydney system. Intestinal metaplasia was noted as absent, complete, or incomplete.

\section{Immunohistochemical staining of CD10, MUC2, MUC5AC, MUC6, and RUNX3}

All mucosal tissues were immediately fixed in $10 \%$ buffered formalin and routinely processed. For each tissue block, $4-\mu \mathrm{m}$-thick serial, paraffin-embedded tissue sections were cut and stained with hematoxylin and eosin. Sections containing glandular epithelium were selected for this study. The samples were deparaffinized in xylene and rehydrated in graded ethanol. Endogenous peroxidase activity was blocked with $3 \% \mathrm{H}_{2} \mathrm{O}_{2}$ in phosphatebuffered saline. For antigen retrieval, the sections were incubated in $10 \mathrm{mM}$ citrate buffer ( $\mathrm{pH}$ 6.0), using a microwave oven, and then incubated with primary antibodies. The primary antibodies used were: MUC2 (1: 200, clone Ccp58, monoclonal; Novocastra Laboratories, Newcastle upon Tyne, UK), MUC5AC (1: 100, clone CLH2, monoclonal; Novocastra Laboratories), MUC6 (1: 100, clone CLH5, monoclonal; Novocastra Laboratories), CD10 (1:400, clone 56C6, monoclonal; Novocastra Laboratories), and RUNX3 (1:200, AMC-2/RUNX3 rabbit polyclonal antibody; Active Motif, Carlsbad, CA, USA). Antibody detection was performed using the IMPRESS peroxidase reagent kit (Vector Laboratories, Burlingame, CA, USA) according to the manufacturer's protocol. Immunoreactive cells were identified using a DAB peroxidase substrate kit (Vector Laboratories). The sections were counterstained with hematoxylin.

\section{Assessment of immunohistochemical staining}

The results of immunostaining for CA10, MUC2, MUC5AC, MUC6, and RUNX3 were considered positive if more than $10 \%$ of the tumor cells were stained [16-18]. The expressions of MUC2 and CD10 were examined as markers for intestinal phenotypes and MUC6 and MUC5AC expressions were considered as markers for gastric phenotypes. The cellular mucin phenotypes were classified according to the combined expression patterns of the gastric markers and intestinal markers, as four phenotypes: gastric type (tumor cells were positive for either MUC6 or MUC5AC, and negative for both MUC2 and CD10; G type), intestinal type (tumor cells were positive for either MUC2 or CD10, and negative for both MUC6 and MUC5AC; I type), mixed type (tumor cells were positive for both gastric and intestinal markers; $M$ type), and an unclassified phenotype (tumor cells were negative for both gastric and intestinal markers; $\mathrm{N}$ type) $[10,19]$. 


\section{Statistical analysis}

For the quantitative variables, the mean values and SD were calculated. For the qualitative variables, the percentages and their $95 \%$ confidence intervals (95\% CIs) were calculated. For comparisons of age and gastritis scores, we used the unpaired $t$-test and one-way analysis of variance (ANOVA). In addition, the $\chi^{2}$ test and linear by linear association was used to investigate the association with other variables (H. pylori status, endoscopic and pathological findings, and immunological results). A binary logistic regression model was used for multivariate analysis. The SPSS statistical package software for Windows release 12.0 (SPSS, Chicago, IL, USA) was used for all analyses. Significance was defined as a $P$ value of less than 0.05 .

\section{Results}

A total of 120 tissue samples were analyzed and 14 tissue samples were excluded because of disagreement about the diagnosis or because of inappropriate preparation of tissue samples. The concordance rate between the two histopathologists was $88.3 \%$. The data of the remaining 106 patients with gastric epithelial dysplasia and intramucosal cancer were evaluated for this study. According to the revised Vienna classification, 52 category 3 tissue samples (low-grade adenoma; from 26 men and 26 women; mean age, $62.52 \pm 4.19$ years) and 54 category 4 tissue samples (from 39 men and 15 women; mean age, $63.80 \pm 4.20$ years) were obtained. Of the category 4 gastric epithelial neoplasias, 35 tissues were high-grade adenomas (category 4.1) and 19 were intramucosal carcinomas with adenomas (category 4.4).

\section{Endoscopic characteristics of gastric epithelial neoplasia}

We reviewed the data on the type, size, color change, ulceration, and location of the lesions by using the imaging archiving communication system. The category 4 lesions were significantly associated with larger size lesions, red color changes, and the presence of ulceration. The distribution of lesion locations was similar in category 4 and category 3 lesions (Table 1 ).

\section{Patterns of gastritis in the surrounding mucosa evaluated by pathological and endoscopic findings}

The gastritis scores for category 3 and 4 lesions were $2.27 \pm 0.95$ and $2.69 \pm 1.10$, respectively; category 4 lesions had higher values than category 3 lesions $(P=$ 0.04). The other variables, including status of $H$. pylori, intestinal metaplasia, and the morphometric changes of gastric mucosal atrophy did not show significant differences (Table 2).
Table 1. Characteristics of gastric epithelial neoplasia categorized by the revised Vienna classification

\begin{tabular}{lccc}
\hline & Category 3 & Category 4 & $P$ value \\
\hline Type & & & \\
$\quad$ Elevated & $35(67.3)$ & $36(66.7)$ & 0.088 \\
$\quad$ Flat & $12(23.1)$ & $6(11.1)$ & \\
$\quad$ Depressed & $5(9.6)$ & $12(22.2)$ & \\
$\begin{array}{l}\text { Size } \\
\text { Color change }\end{array}$ & $1.59 \pm 0.65$ & $2.03 \pm 1.00$ & 0.009 \\
$\quad$ Normal or whitish & $38(73.1)$ & $28(51.9)$ & 0.024 \\
$\quad$ Reddish & $14(26.9)$ & $26(48.1)$ & \\
Ulcer & & & \\
$\quad(+)$ & $8(15.4)$ & $23(42.6)$ & 0.002 \\
$\quad(-)$ & $44(84.6)$ & $31(57.4)$ & \\
Location & & & \\
$\quad$ Antrum & $37(71.2)$ & $44(81.5)$ & 0.211 \\
$\quad$ Body/Cardia & $15(28.8)$ & $10(18.5)$ & \\
\hline
\end{tabular}

Table 2. Gastritis pattern of gastric mucosa surrounding gastric epithelial neoplasia

\begin{tabular}{lccc}
\hline & Category 3 & Category 4 & $P$ value \\
\hline Gastritis score & $2.27 \pm 0.95$ & $2.69 \pm 1.10$ & $0.040^{*}$ \\
Helicobacter pylori & & & \\
$\quad$ Positive & $24(46.2)$ & $25(46.3)$ & 0.988 \\
$\quad$ Negative & $28(53.8)$ & $29(53.7)$ & \\
Intestinal metaplasia & & & \\
$\quad$ No & $2(3.8)$ & $3(5.6)$ & 0.917 \\
$\quad$ Incomplete & $45(86.5)$ & $46(85.2)$ & \\
$\quad$ Complete & $5(9.6)$ & $5(9.3)$ & \\
Atrophy & & & \\
$\quad$ Closed type & $16(30.8)$ & $18(33.3)$ & 0.761 \\
$\quad$ Open type & $36(69.2)$ & $36(66.7)$ & \\
\hline
\end{tabular}

* Significant difference between categories 3 and 4

Immunoreactivity of MUC2, MUC5AC, MUC6, and $C D 10$

The microscopic features of the immunohistochemical staining for MUC2, MUC5AC, MUC6, and CD10 are presented in Figs 1 and 2. Of the 52 cases included in category 3, MUC2, MUC5AC, MUC6, and CD10 were expressed in $30(57.7 \%), 15$ (28.8\%), 3 (5.8\%), and 20 $(38.5 \%)$ cases, respectively. Of the 54 cases included in category 4, MUC2, MUC5AC, MUC6, and CD10 were expressed in $32(59.3 \%), 22(40.7 \%), 14$ (25.9\%), and 18 $(33.3 \%)$ cases, respectively. MUC6 expression was more frequently observed in category 4 than in category 3 lesions $(P=0.005$; Table 3$)$. When the lesions were subgrouped into high-grade dysplasia (category 4.1) and intramucosal cancer (category 4.4), positive expression of MUC6 was observed in 7 cases $(7 / 36 ; 19.4 \%)$, and 7 cases $(7 / 19 ; 36.8 \%)$, respectively $(P=0.002)$. Taking into account the combination of expression of the gastric (MUC6 and MUC5AC) and intestinal (MUC2 and CD10) markers, the gastric epithelial neoplasias were classified into four mucin phenotypes. For category 3 

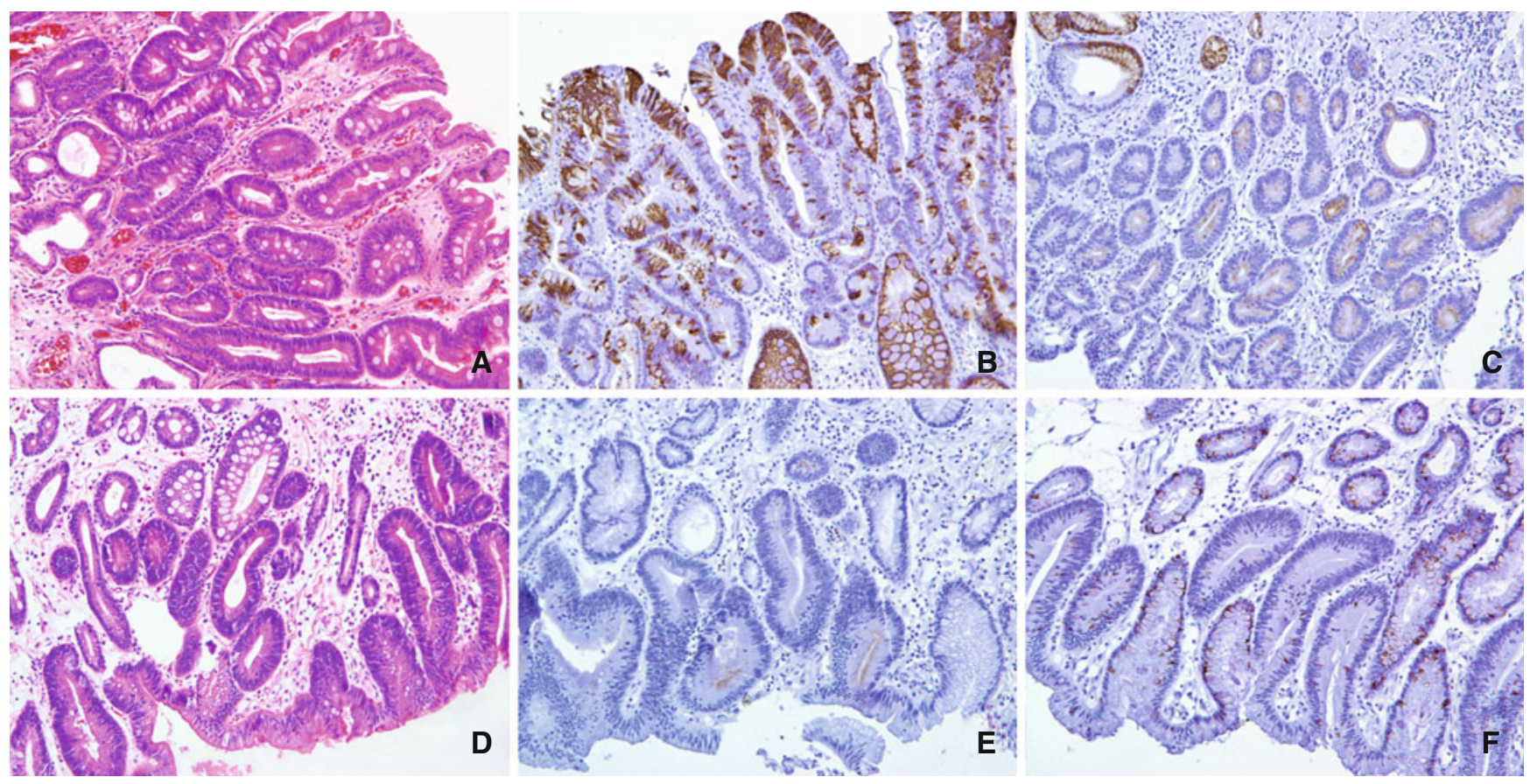

Fig. 1. A-C Histological and immunohistochemical findings from a complete gastric phenotype in category 3 gastric epithelial neoplasia (A, H\&E; B, MUC5A; C, MUC6 stain $\times 100)$. D-F Histological and immunohistochemical findings from an intestinal phenotype (D, H\&E; E, CD10; F, MUC2 stain $\times 100)$
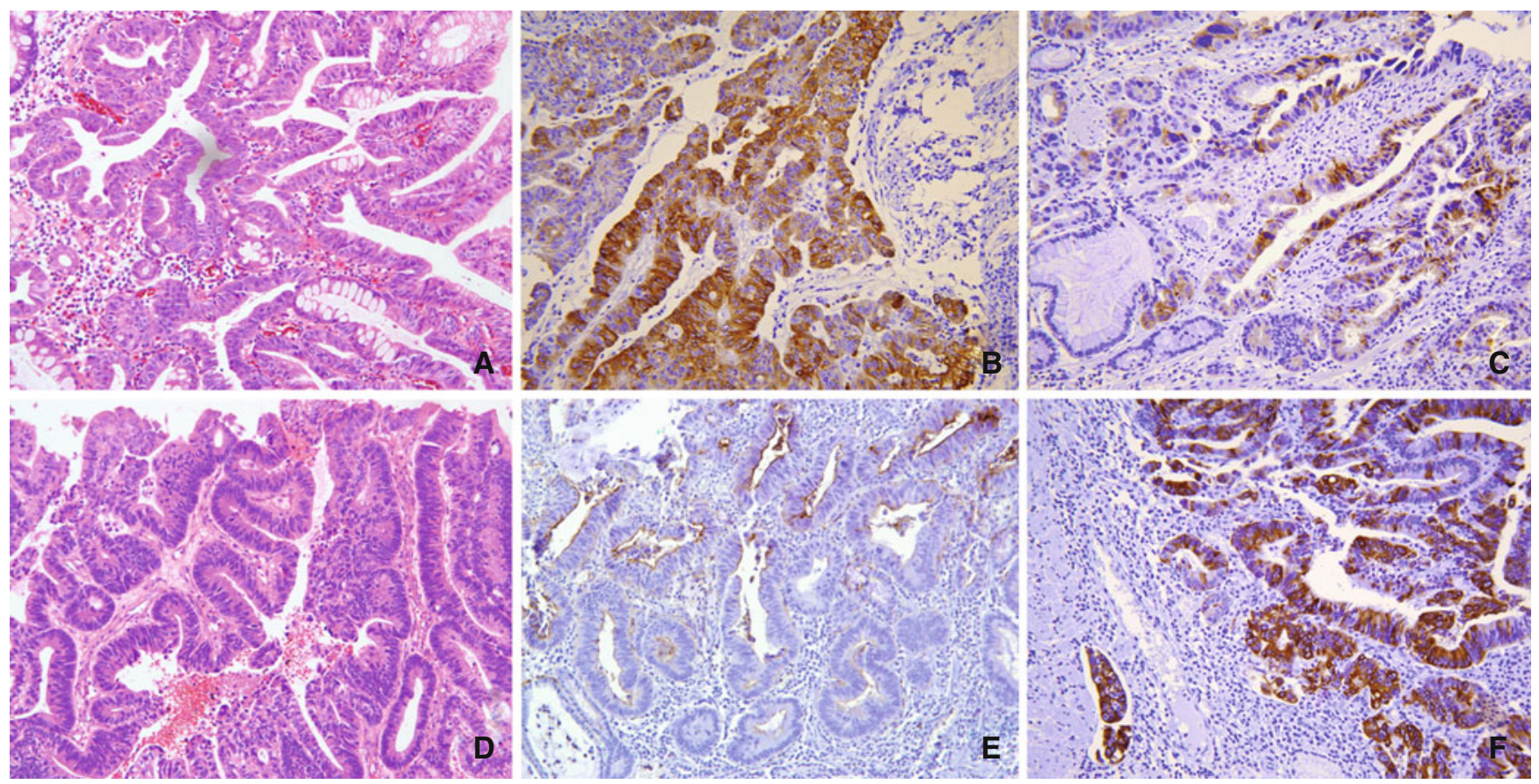

Fig. 2. A-C Histological and immunohistochemical findings from a complete gastric phenotype in category 4 gastric epithelial neoplasia (A, H\&E; B, MUC5A; C, MUC6 stain $\times 100)$. D-F Histological and immunohistochemical findings from an intestinal phenotype (D, H\&E; E, CD10; F, MUC2 stain $\times 100)$ 
lesions, there was the gastric phenotype in $8(15.4 \%)$ cases, the intestinal phenotype in $30(57.7 \%)$ cases, the mixed phenotype in $7(13.5 \%)$ cases, and an unclassified phenotype in $7(13.5 \%)$ cases. For category 4 lesions, there was the gastric phenotype in $11(20.4 \%)$ cases, the intestinal phenotype in $19(35.2 \%)$ cases, the mixed phenotype in $18(33.3 \%)$ cases, and the unclassified phenotype in $6(11.1 \%)$ cases.

\section{Immunoreactivity of RUNX3}

The microscopic features of RUNX3 immunohistochemical staining are presented in Fig. 3. Among the

Table 3. Expression of MUC2, MUC5AC, MUC6, and CD10 in gastric epithelial neoplasia

\begin{tabular}{cccc}
\hline & Category 3 & Category 4 & $P$ value \\
\hline $\begin{array}{l}\text { MUC2 } \\
(-)\end{array}$ & $22(42.3)$ & $22(40.7)$ & 0.870 \\
$(+)$ & $30(57.7)$ & $32(59.3)$ & \\
$\begin{array}{c}\text { MUC5AC } \\
(-)\end{array}$ & $37(71.2)$ & $32(59.3)$ & 0.199 \\
$(+)$ & $15(28.8)$ & $22(40.7)$ & \\
$\begin{array}{c}\text { MUC6 } \\
(-)\end{array}$ & $49(94.2)$ & $40(74.1)$ & 0.005 \\
$(+)$ & $3(5.8)$ & $14(25.9)$ & \\
CD 10 & $32(61.5)$ & $36(66.7)$ & 0.582 \\
$(-)$ & $20(38.5)$ & $18(33.3)$ & \\
$(+)$ & & & \\
\hline
\end{tabular}

52 cases of category 3 lesions, positive expression of RUNX3 was observed in 27 (51.9\%) cases, and positive RUNX3 expression was observed in 18 (33.3\%) cases of the 54 category 4 lesions; there was no significant difference $(P=0.053)$ and there was a decreasing tendency in category 4 lesions. When the lesions were subgrouped into high-grade dysplasia (category 4.1) and intramucosal cancer (category 4.4), positive expression of RUNX3 was observed in 15 cases $(15 / 36 ; 41.7 \%)$, and 3 cases $(3 / 19 ; 15.8 \%)$, respectively $(P=0.007)$.

\section{Multivariate analysis}

Multivariate analysis of the covariates that showed statistical significance in the univariate analysis was performed; the results showed that a diameter of more than $17 \mathrm{~mm}$, the presence of ulceration and positive expression of MUC6 were strongly associated with category 4 lesions (Table 4).

\section{Discussion}

With the increasing use of endoscopic therapy such as endoscopic mucosal resection, it is very important to agree on the diagnosis of gastric epithelial neoplasia. After the revised Vienna classification was introduced, agreement on the diagnosis improved to $80 \%$ for gastric lesions [20]. However, this classification is not perfect

Table 4. Multivariate analysis for the factors predicting category 4

\begin{tabular}{lcccc}
\hline Total & $\beta$ & Odds ratio & $95 \% \mathrm{CI}^{*}$ & $P$ value \\
\hline $\begin{array}{l}\text { Inflammatory score } \\
\quad \leq 3 \mathrm{vs} \geq 4\end{array}$ & 0.445 & 1.561 & $0.458-5.320$ & 0.477 \\
$\begin{array}{l}\text { Size } \\
\quad \leq 1.6 \mathrm{~cm} \text { vs } \geq 1.7 \mathrm{~cm}\end{array}$ & 1.060 & 2.886 & $1.163-7.164$ & 0.022 \\
$\quad \begin{array}{l}\text { Ulcer } \\
\quad \text { Negative vs positive }\end{array}$ & 1.319 & 3.741 & $1.154-12.124$ & 0.028 \\
$\quad \begin{array}{l}\text { Color change } \\
\quad \text { Normal or whitish vs reddish }\end{array}$ & 0.338 & 1.402 & $0.521-3.771$ & 0.503 \\
$\begin{array}{l}\text { MUC6 } \\
\quad \text { Negative vs positive }\end{array}$ & 1.402 & 4.062 & $1.009-16.355$ & 0.049 \\
$\quad$ CI, confidence interval & & & & \\
\end{tabular}
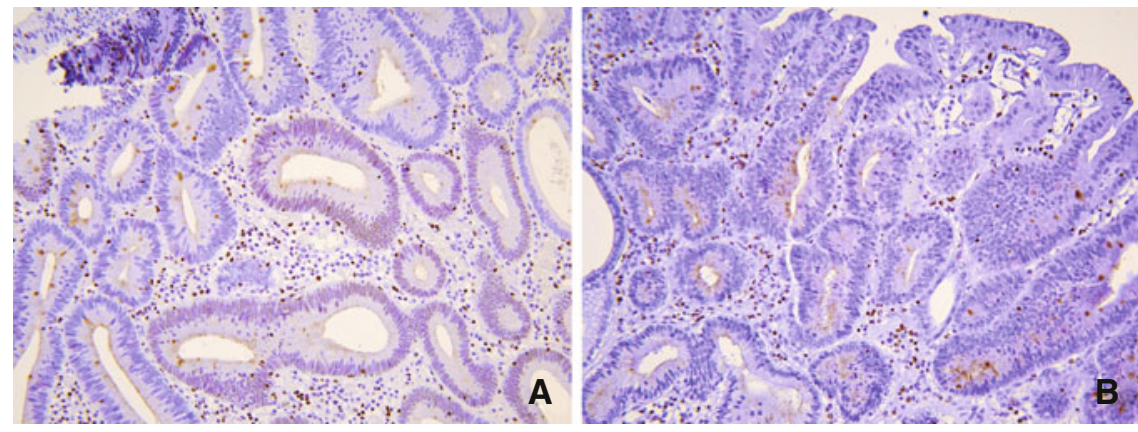

Fig. 3A,B. Positive expression of RUNX3 in nucleus and cytoplasm. Immunohistochemical staining findings: $\mathbf{A}$ in category 3 lesion $(\times 200)$; $\mathbf{B}$ in category 4 lesion $(\times 100)$ 
and it requires the consideration of additional information, including endoscopic findings, pathology, and immunological feature, as well as molecular markers. In addition, the frequency of discrepant diagnoses between biopsy specimens and the corresponding resected specimens of the same lesions has ranged from $20 \%$ to $40 \%$ in previous reports [21-23]. In the clinical setting, many physicians have difficulty with decisions on their therapeutic plan because of uncertainty with regard to the interpretation of biopsy reports. Therefore, complete removal of the entire epithelial lesion is recommended to confirm the diagnosis. In the present study, we attempted to eliminate diagnostic bias in the biopsy specimen and evaluated specimens excised by endoscopic mucosal resection.

Identification of a gastric adenoma that has the potential to progress to cancer is an important consideration for the therapeutic plan. In general, the risk of malignant transformation, for an adenoma, depends on its size, histological type, and the presence of atrophy [2426]. The tumor size is considered to be an important prognostic marker; however, several studies have not provided evidence to support the importance of this variable $[24,27]$. Our present results showed that by univariate analysis, the size of the lesion, red color changes, presence of ulceration, gastritis score of the surrounding mucosa, and immunoreactivity of MUC6 were risk factors for malignant change. The multivariate analysis showed that the size of the lesion, ulceration, and immunoreactivity of MUC6 were associated with early changes of malignancy. Especially for macroscopic examination, the lesion size and presence of ulceration are simple and important factors that can be used for reaching therapeutic decisions; assessment of these factors might help reduce the overtreatment of lesions such as surgical treatment of low grade adenoma.

Mucins are the main structural components of mucus; they are highly glycosylated, high-molecular weight glycoproteins [28]. In general, normal gastric epithelium of the antrum is characterized by the expression of secretory mucins: MUC5AC and MUC6. Intestinal metaplasia of the stomach is characterized by the expression of MUC2 and CD10, whereas the expression of MUC5AC and MUC6 is reduced in intestinal metaplasia [29, 30]. Moreover, $H$. pylori-infected gastric surface epithelium protects itself by the downregulation of MUC5AC and the upregulation of MUC6; this process forms a mucus gel-layer to protect the underlying epithelium [31, 32]. The phenotypic expression of tumor markers is thought to imitate the tissue of origin; such expression of tumor markers is associated with tumor aggressiveness in advanced gastric cancer [33]. It is known that malignant transformation from a gastric adenoma to a carcinoma is significantly associated with the gastric and the intestinal mixed phenotypes [34, 35]. Our present results revealed that the gastric and mixed phenotypes were increased in category 4 lesions compared with findings in the category 3 lesions; however, these differences did not reach statistical significance. In a recent report, phenotypic marker expression was closely associated with genetic alterations, especially microsatellite instability, which is significantly associated with MUC6 expression. Moreover, MUC6 is upregulated by nuclear factor (NF)- $\mathrm{KB}$, a nuclear transcription factor that is also activated in inflammatory and neoplastic conditions [36-38]. It is noteworthy that positive immunoreactivity of MUC6 was found to be a risk factor for malignant change by the univariate and multivariate analyses in the present study. Positive immunoreactivity of MUC6 in the areas of gastric epithelial neoplasia with highgrade dysplasia and intramucosal cancer suggests that MUC6 might play a role in malignant transformation, and MUC6 might be a useful marker for distinguishing lesions at risk of malignant transformation. However, to clarify these risk factors, a different study plan would be required; that is, a prospective or retrospective study would be needed to examine whether or not category 3 lesions, determined by biopsy diagnosis, associated with any of the factors demonstrated in the present study (size more than $17 \mathrm{~mm}$, ulceration, MUC6 expression), had developed to category 4 lesions.

Gastric inflammation is already considered a risk factor for gastric carcinoma [39, 40]. Previously, Correa [41] postulated that chronic gastritis may lead to intestinal metaplasia and atrophy, and noted that these findings should be considered a risk factor for the development of cancer, because they are frequently found to be closely related to cancer. Herein we focused on the acute and chronic inflammation around gastric epithelial neoplasias and investigated these findings with regard to malignant changes. Contrary to the findings in a previous study [42], we divided intestinal metaplasia (IM) into three categories: absent, incomplete, and complete IM and evaluated them as independent variables. IM has been extensively studied as a precancerous lesion of the human stomach; it has been shown to have a strong association with the development of stomach cancer [43-46]. Gastric atrophy is defined as the loss of specialized glands; however, there is essentially no agreement among pathologists on the assessment of gastric atrophy. One goal of the present study was to increase interobserver agreement on atrophy by using a morphometric diagnosis that corresponds to a serological gastric profile of atrophy, as previously reported [47]. Our results showed that IM and atrophy were not significantly different. However, the activity and grade of gastritis in category 4 lesions had higher values than those in category 3 lesions. Considering that $H$. pylori is recognized as the major pathogenetic factor associated with chronic active gastritis, the eradication of this bac- 
terium should help block the progression of gastric dysplasia. Whether H. pylori eradication is beneficial at the dysplastic stage of the gastric epithelium requires further study.

RUNX3 is a novel tumor suppressor gene; it is frequently silenced in gastric cancers by the hypermethylation of $\mathrm{CpG}$ islands in the exon 1 region [12, 13, 48]. Immunohistochemistry results showed the RUNX3 protein in most chief cells and in a few gastrin-containing $\mathrm{G}$ cells in normal mucosa, but not in IM or carcinoma cells [49]. Although RUNX3 immunoreactivity showed no significant difference between category 3 and 4 lesions in the present study, negative expression of RUNX3 was more frequent in intramucosal cancers than in dysplasias. The loss of function of RUNX3 might be a very early event in the progression of gastric carcinogenesis.

In conclusion, the size, color change, ulceration, gastritis score of the surrounding mucosa, and positive expression of MUC6 were significant variables that might be involved in the malignant transformation of gastric dysplasia. The findings of a lesion more than $17 \mathrm{~mm}$ in diameter or ulceration are important factors to consider for therapeutic decisions. In addition, MUC6 expression may be a novel marker for the risk of malignant change.

\section{References}

1. Kamiya T, Morishita T, Asakura H, Miura S, Munakata Y, Tsuchiya M. Long-term follow-up study on gastric adenoma and its relation to gastric protruded carcinoma. Cancer 1982;50:2496-503.

2. Orlowska J, Jarosz D, Pachlewski J, Butruk E. Malignant transformation of benign epithelial gastric polyps. Am J Gastroenterol 1995;90:2152-9.

3. Schlemper RJ, Kato Y, Stolte M. Well-differentiated adenocarcinoma or dysplasia of the gastric epithelium: rationale for a new classification system. Verh Dtsch Ges Pathol 1999;83:6270 .

4. Stolte M. Diagnosis of gastric carcinoma: Japanese fairy tales or Western deficiency? Virchows Arch 1999;434:279-80.

5. Schlemper RJ, Riddell RH, Kato Y, Borchard F, Cooper HS, Dawsey SM, et al. The Vienna classification of gastrointestinal epithelial neoplasia. Gut 2000;47:251-5.

6. Stolte M. The new Vienna classification of epithelial neoplasia of the gastrointestinal tract: advantages and disadvantages. Virchows Arch 2003;442:99-106.

7. Lauwers GY, Riddell RH. Gastric epithelial dysplasia. Gut 1999; 45:784-90.

8. Takenawa H, Kurosaki M, Enomoto N, Miyasaka Y, Kanazawa N, Sakamoto N, et al. Differential gene-expression profiles associated with gastric adenoma. Br J Cancer 2004;90:216-23.

9. Park SY, Jeon SW, Jung MK, Cho CM, Tak WY, Kweon YO, et al. Long-term follow-up study of gastric intraepithelial neoplasias: progression from low-grade dysplasia to invasive carcinoma. Eur J Gastroenterol Hepatol 2008;20:966-70.

10. Tsukashita S, Kushima R, Bamba M, Sugihara H, Hattori T. MUC gene expression and histogenesis of adenocarcinoma of the stomach. Int J Cancer 2001;94:166-70.
11. Minematsu H, Saito Y, Kakinoki R, Andoh A, Kushima R, Fujiyama Y. Evaluation of mucin expression patterns in gastric borderline (group III) lesions. J Gastroenterol 2006;41:547-53.

12. Lund AH, van Lohuizen M. RUNX: a trilogy of cancer genes. Cancer Cell 2002;1:213-5.

13. Li QL, Ito K, Sakakura C, Fukamachi H, Inoue K, Chi XZ, et al. Causal relationship between the loss of RUNX3 expression and gastric cancer. Cell 2002;109:113-24.

14. Chi XZ, Yang JO, Lee KY, Ito K, Sakakura C, Li QL, et al. RUNX3 suppresses gastric epithelial cell growth by inducing p21(WAF1/ Cip1) expression in cooperation with transforming growth factor \{beta\}-activated SMAD. Mol Cell Biol 2005;25:8097-107.

15. Dixon MF, Genta RM, Yardley JH, Correa P. Classification and grading of gastritis. The updated Sydney system. International workshop on the histopathology of gastritis, Houston 1994. Am J Surg Pathol 1996;20:1161-81.

16. Kocer B, Soran A, Kiyak G, Erdogan S, Eroglu A, Bozkurt B, et al. Prognostic significance of mucin expression in gastric carcinoma. Dig Dis Sci 2004;49:954-64.

17. Tajima Y, Shimoda T, Nakanishi Y, Yokoyama N, Tanaka T, Shimizu $\mathrm{K}$, et al. Gastric and intestinal phenotypic marker expression in gastric carcinomas and its prognostic significance: immunohistochemical analysis of 136 lesions. Oncology 2001;61:212-20.

18. Wakatsuki K, Yamada Y, Narikiyo M, Ueno M, Takayama T, Tamaki H, et al. Clinicopathological and prognostic significance of mucin phenotype in gastric cancer. J Surg Oncol 2008;98: 124-9.

19. Shiroshita H, Watanabe H, Ajioka Y, Watanabe G, Nishikura K, Kitano S. Re-evaluation of mucin phenotypes of gastric minute well-differentiated-type adenocarcinomas using a series of HGM, MUC5AC, MUC6, M-GGMC, MUC2 and CD10 stains. Pathol Int 2004;54:311-21.

20. Schlemper RJ, Kato Y, Stolte M. Review of histological classifications of gastrointestinal epithelial neoplasia: differences in diagnosis of early carcinomas between Japanese and Western pathologists. J Gastroenterol 2001;36:445-56.

21. Sung HY, Cheung DY, Cho SH, Kim JI, Park SH, Han JY, et al. Polyps in the gastrointestinal tract: discrepancy between endoscopic forceps biopsies and resected specimens. Eur J Gastroenterol Hepatol 2009;21:190-5.

22. Yoon WJ, Lee DH, Jung YJ, Jeong JB, Kim JW, Kim BG, et al. Histologic characteristics of gastric polyps in Korea: emphasis on discrepancy between endoscopic forceps biopsy and endoscopic mucosal resection specimen. World J Gastroenterol 2006;12: 4029-32.

23. Szalóki T, Tóth V, Tiszlavicz L, Czakó L. Flat gastric polyps: results of forceps biopsy, endoscopic mucosal resection, and long-term follow-up. Scand J Gastroenterol 2006;41:1105-9.

24. Park DI, Rhee PL, Kim JE, Hyun JG, Kim YH, Son HJ, et al. Risk factors suggesting malignant transformation of gastric adenoma: univariate and multivariate analysis. Endoscopy 2001;33:501-6.

25. Tabata H, Fuchigami T, Kobayashi H, Sakai Y, Nakanishi M, Tomioka K, et al. Difference in degree of mucosal atrophy between elevated and depressed types of gastric epithelial tumors. Scand J Gastroenterol 2001;36:1134-40.

26. Vieth M, Stolte M. Elevated risk for gastric adenocarcinoma can be predicted from histomorphology. World J Gastroenterol 2006; 12:6109-14.

27. Jung MK, Jeon SW, Park SY, Cho CM, Tak WY, Kweon YO, et al. Endoscopic characteristics of gastric adenomas suggesting carcinomatous transformation. Surg Endosc 2008;22:2705-11.

28. Carraway KL, Fregien N. Mucin structure and function: insights from molecular biology. Trends Glycosci Glycotechnol 1995;33: $31-44$.

29. Ho SB, Niehans GA, Lyftogt C, Yan PS, Cherwitz DL, Gum ET, et al. Heterogeneity of mucin gene expression in normal and neoplastic tissues. Cancer Res 1993;53:641-51.

30. Reis CA, David L, Correa P, Carneiro F, de Bolós C, Garcia E, et al. Intestinal metaplasia of human stomach displays distinct 
patterns of mucin (MUC1, MUC2, MUC5AC, and MUC6) expression. Cancer Res 1999;59:1003-7.

31. Morgenstern S, Koren R, Moss SF, Fraser G, Okon E, Niv Y. Does Helicobacter pylori affect gastric mucin expression? Relationship between gastric antral mucin expression and $H$. pylori colonization. Eur J Gastroenterol Hepatol 2001;13:19-23.

32. Kang HM, Kim N, Park YS, Hwang JH, Kim JW, Jeong SH, et al. Effects of Helicobacter pylori infection on gastric mucin expression. J Clin Gastroenterol 2008;42:29-35.

33. Yoshikawa A, Inada Ki K, Yamachika T, Shimizu N, Kaminishi M, Tatematsu M. Phenotypic shift in human differentiated gastric cancers from gastric to intestinal epithelial cell type during disease progression. Gastric Cancer 1998;1:134-41.

34. Tatematsu M, Ichinose M, Miki K, Hasegawa R, Kato T, Ito N. Gastric and intestinal phenotypic expression of human stomach cancers as revealed by pepsinogen immunohistochemistry and mucin histochemistry. Acta Pathol Jpn 1990;40:494504.

35. Endoh Y, Sakata K, Tamura G, Ohmura K, Ajioka Y, Watanabe H, et al. Cellular phenotypes of differentiated type adenocarcinomas and precancerous lesions of the stomach are dependent on the genetic pathways. J Pathol 2000;191:257-63.

36. Sakai H, Jinawath A, Yamaoka S, Yuasa Y. Upregulation of MUC6 mucin gene expression by NFkappaB and Sp factors. Biochem Biophys Res Commun 2005:333:1254-60.

37. Owens SR, Chiosea SI, Kuan SF. Selective expression of gastric mucin MUC6 in colonic sessile serrated adenoma but not in hyperplastic polyp aids in morphological diagnosis of serrated polyps. Mod Pathol 2008;21:660-9.

38. Zheng HC, Li XH, Hara T, Masuda S, Yang XH, Guan YF, et al. Mixed-type gastric carcinomas exhibit more aggressive features and indicate the histogenesis of carcinomas. Virchows Arch 2008; 452:525-34.

39. Meining A, Bayerdorffer E, Muller P, Miehlke S, Lehn N, Holzel D, et al. Gastric carcinoma risk index in patients infected with Helicobacter pylori. Virchows Arch 1998;432:311-4.
40. Miehlke S, Hackelsberger A, Meining A, Hatz R, Lehn N, Malfertheiner $\mathrm{P}$, et al. Severe expression of corpus gastritis is characteristic in gastric cancer patients infected with Helicobacter pylori. Br J Cancer 1998;78:263-6.

41. Correa P. A human model of gastric carcinogenesis. Cancer Res 1988;48:3554-60.

42. Meining A, Stolte M, Hatz R, Lehn N, Miehlke S, Morgner A, et al. Differing degree and distribution of gastritis in Helicobacter pylori-associated diseases. Virchows Arch 1997;431:11-5.

43. Matsukura N, Suzuki K, Kawachi T, Aoyagi M, Sugimura T, Kitaoka H, et al. Distribution of marker enzymes and mucin in intestinal metaplasia in human stomach and relation to complete and incomplete types of intestinal metaplasia to minute gastric carcinomas. J Natl Cancer Inst 1980;65:231-40.

44. Morson BC. Carcinoma arising from areas of intestinal metaplasia in the gastric mucosa. Br J Cancer 1955;9:377-85.

45. Filipe MI, Munoz N, Matko I, Kato I, Pompe-Kirn V, Jutersek A, et al. Intestinal metaplasia types and the risk of gastric cancer: a cohort study in Slovenia. Int J Cancer 1994;57:324-9.

46. You WC, Blot WJ, Li JY, Chang YS, Jin ML, Kneller R, et al. Precancerous gastric lesions in a population at high risk of stomach cancer. Cancer Res 1993;53:1317-21.

47. Nardone G, Rocco A, Staibano S, Mezza E, Autiero G, Compare $\mathrm{D}$, et al. Diagnostic accuracy of the serum profile of gastric mucosa in relation to histological and morphometric diagnosis of atrophy. Aliment Pharmacol Ther 2005;22:1139-46.

48. Bae SC, Takahashi E, Zhang YW, Ogawa E, Shigesada K, Namba $\mathrm{Y}$, et al. Cloning, mapping and expression of PEBP2 alpha C, a third gene encoding the mammalian Runt domain. Gene 1995; 159:245-8.

49. Osaki M, Moriyama M, Adachi K, Nakada C, Takeda A, Inoue Y, et al. Expression of RUNX3 protein in human gastric mucosa, intestinal metaplasia and carcinoma. Eur J Clin Invest 2004;34: $605-2$. 